\title{
Nutritional Supplements : Taste Preferences in Patients with Malignant Haematological Disease during Active Treatment
}

\author{
Gry Bjerg Petersen and Jens Rikardt Andersen
}

Clinic for Haematology and Nutrition Unit, Rigshospitalet, and Dept Nutrition, Exercise and Sports, University of Copenhagen, Denmark

Correspondence should be addressed to: Jens Rikardt Andersen; jra@life.ku.dk

Received date: 21 November 2013; Accepted date: 14 April 2014; Published date: 24 April 2015

Academic Editor: Federico Bozzetti

Copyright (C) 2015. Gry Bjerg Petersen and Jens Rikardt Andersen. Distributed under Creative Commons CC-BY 4.0

\begin{abstract}
Background: Several studies have indicated that cancer patients have significantly altered taste sensitivity without specifying the preferences. One of the related problems is low compliance to nutritional therapy with oral nutritional supplements (ONS) in patients suffering severe weight loss. Objective: We wanted to investigate taste preferences and sensoric characteristics among three usually used ONS in patients with malignant haematological disease during cytotoxic treatment. Design: Tested drinks were: Protin $\AA$ (protein-enriched-milk, ARLA), Nutridrink® (NUTRICIA) and hospital-produced drink of buttermilk and egg (RH-drink), all with vanilla taste. Protein-contents were the same (5-6 $\mathrm{g} / 100 \mathrm{ml}$ ). Forty-one consecutive patients tasted the three ONS in a randomized, blinded set-up with one of the ONS included twice as a control. Taste qualities were quantified on VAS-scales: Bitter, sweet, salt, sour, metal, gritty, consistence and ability to drink $150 \mathrm{ml}$ (one glass), and the patients arranged the drinks in order of preference. Results: The sensory qualities differed significantly concerning sweet $(p<0.05)$, sour $(p<0.008)$ and the ability to drink $150 \mathrm{ml}$. Patients preference order was Protin ${ }^{\circledR}(\mathrm{p}<0.002)$ as the best, $\mathrm{RH}-$ drink next $(\mathrm{p}<0.005)$ and Nutridrink ${ }^{\circledR}$ last. Conclusions: Patients in cytostatic therapy had clear preferences for fresh, hyperosmolar, milk-based ONS without vitamins, and had major difficulties with a commercial product. The preferences were not related to osmolarity.
\end{abstract}

Keywords: Oral nutritional supplements, malignant haematological diseases, taste, compliance

\section{Introduction}

Patients with solid cancers lose weight and have decreased appetite, early saturation and nausea mainly related to the tumour burden (Ravasco et al, 2003), but also correlated to intake deficits (Ravasco et al,
2007). Comparable results are not available in haematological cancers, but at least during the cytotoxic therapy it is the clinical experience, that the nutritional problems are even more pronounced than in patients with solid cancers. In patients with malignant haematological disease 
with high-dose chemotherapy and often stem-cell transplantation, changes in taste and smell appear with particular difficulty in differentiating sour and bitter (Epstein et al, 2002). In these hyper metabolic cancer patients, protein-intake is important due to gluconeogenesis, with a loss of lean body mass (LBM). This loss of LBM can potentially be reduced by protein supplements as an integrated part of dietary counselling, but it is only shown in patients with colorectal cancer undergoing radiotherapy (Ravasco et al, 2005). However, poor compliance often results in patients not reaching their nutritional goals (Ravasco, 2005), and part of this are tasterelated problems. Nutritional supplements are developed in an industrial setting and analysis of taste is very often done in a laboratory by a censoring panel. This setting and these censors are quite different from the patients. Patients with gastro-intestinal cancers seem to prefer fresh-milk-based supplements to UHT milk based (Ultra High Temperature) and fruit juice based, also during chemotherapy. However, vitamins and minerals were added to both the UTH-milk based and the fruit based products, and all were hyperosmolar (Rahemtulla et al, 2005). No similar studies have been published for patients with malignant, haematological diseases.

This study aimed to determine the patients' preferences for three different ONS including non-vitamin-enriched and freshly made products. We wanted to examine taste perception, and to assess the reproducibility of the taste assessments by means of a Visual Analogue Scale (VAS) in patients with malignant haematological disease.

\section{Methods}

VAS (Visual Analogue Scale)

The reproducibility of VAS is relatively well documented in other scientific areas and is described as a valid measure of subjective phenomenon, but carries a phenomenological problem with an underlying acceptance of linearity, which might not be true (Rødbotten, 1997). In this study a unipolar continuous scale was used to evaluate the sensory variables: sweet, sour, bitter, salt, thickness, gritty and metal and the palatability (the ability to drink a glass of the product $(150 \mathrm{ml}))$. All the VAS-scores were performed immediately after tasting, and at the end of the experiment patients rated the three (four) products 1-3(4), as one was repeated.

\section{Selection of Products}

Three milk-based products were selected, as these were the three mostly used products in the department: Nutridrik ${ }^{\circledR}$ from Nutricia, Koldskål (RH) from the kitchen in Rigshospitalet and Protin $®$ from Arla. The products had the same flavour, Vanilla and had similar protein content (Nutridrik® $\quad 6 \mathrm{~g} / 100 \mathrm{ml}, \quad \operatorname{Protin} \AA$ $5.7 \mathrm{~g} / 100 \mathrm{ml}$ and $\mathrm{RH} 5 \mathrm{~g} / 100 \mathrm{ml}$ ). Nutridrik ${ }^{\circledR}$ is a UHT milk based, hyperosmolar product from Nutricia with added vitamins and minerals with an osmolarity of $450 \mathrm{mOsm} / \mathrm{l}$ (in $100 \mathrm{ml}: 630$ $\mathrm{kJ}, 18.4 \mathrm{~g}$ carbohydrate, $5.8 \mathrm{~g}$ fat). $\mathrm{RH}$ is a fresh cold buttermilk based product with eggs made in the Kitchen on Rigshospitalet from day to day. The recipe for one litre is: Junket 3 dl, buttermilk 6 dl, egg-yolk $80 \mathrm{~g}$, sugar $45 \mathrm{~g}$, and the osmolarity is 653 mOsm/l. Junket, egg and buttermilk is whippet, sugar is added and the taste is adjusted with vanilla sugar and lemon (in $100 \mathrm{ml}: 356 \mathrm{~kJ}, 9.3 \mathrm{~g}$ carbohydrate, $3.1 \mathrm{~g}$ fat). Protin $®$ is a fresh milk based product with added milk-proteins from the diary, Arla with a shelf life of 10 days (open 3 days), osmolarity $718 \mathrm{mOsm} / \mathrm{l}$ (in $100 \mathrm{ml}$ : $540 \mathrm{~kJ}, 12 \mathrm{~g}$ carbohydtate, $6.3 \mathrm{~g}$ fat)..

Taste samples

The products were served in a plastic cup $(4 \mathrm{ml})$ at room temperature in a random rotating order on the same day. The patients were blinded to the products. The samples were served according to a preformed protocol with random allocation of the drinks, and the repeated drink in a random position in the sequence. One of the samples was repeated in every experiment to quantitate reproducibility. 


\section{Viscosity}

The viscosity was determined by the Laboratory of Rheology and Texture, The department of Food Technology, The Technical University of Denmark by the shear stress/shear rate (Pa s). Shear stress is the force that moves the liquid, and shear rate $(1 / s)$ is the velocity gradient.

Subjects

Forty-one patients from the haematological clinic in Rigshospitalet participated in the study (table 1). Patients were asked for participating consecutively on rounds if they fulfilled the inclusion criteria. Inclusion criteria: patients in treatment in one of the four haematological units, no distinction for cancer type, gender or type of treatment. The time interval from the last chemotherapy or radiation therapy varied from two weeks to two months. All the patients had severe eating problems at the time of investigation, and all had mucositis visually diagnosed. All patients were of legal age and mentally able to understand written and verbal information. Exclusion criteria: use of parenteral nutrition or tube feeding, lack of ability to communicate and/or cooperate. All patients gave written consent.

The protocol was approved by the regional ethical committee.

Table 1: Baseline characteristics for 41 patients with haematological malignant disease and mucositis.

\begin{tabular}{|l|c|c|}
\hline Number of subject & \multicolumn{1}{|l|}{$\mathbf{S 1}$} & SD/range \\
\hline Age & 53 years & $34-70$ \\
\hline Weight & $74.5 \mathrm{~kg}$ & $17.8 \mathrm{~kg}$ \\
\hline Height & $175.4 \mathrm{~cm}$ & $10.96 \mathrm{~cm}$ \\
\hline BMI & 24.1 & 4.87 \\
\hline Diagnosis & & \\
\hline Leukaemia & 26 & \\
\hline Multiple myeloma & 8 & \\
\hline Myelofibrosis & 1 & \\
\hline TTP & 1 & \\
\hline Non-Hodgkin-lymphoma & 2 & \\
\hline Uncertain diagnosis & 3 & \\
\hline Previous Treatment & & \\
\hline Cytostatic & 10 & \\
\hline Stem cell treatment & 2 & \\
\hline Transplantation & 7 & \\
\hline GVH (graft versus host) & 1 & \\
\hline Blood transfusion & 1 & \\
\hline Medicine adjustment & 8 & \\
\hline Radiation & 2 & \\
\hline No cancer-treatment & 10 & \\
\hline
\end{tabular}

\section{Results}

VAS

The patients' median and average VAS scores for the 3 drinks were similar (table 2), 
Table 2: Average and median score of the sensory variables for Protin, RH and Nutridrik. The numbers are in $\mathrm{cm}$ measured on a $10 \mathrm{~cm}$ VAS scale. Sensory parameters 0: Too much of the variable, 10: Too little of the variable. Drink a glass 0: Not alt all, 10: No problem. In 41 patients with haematological malignant disease

\begin{tabular}{|l|l|l|l|l|l|l|l|l|}
\hline Product & Bitter & A glass & Sweet & Gritty & Metal & Salt & Sour & Thickness \\
\hline $\begin{array}{l}\text { Protin } \\
\text { n=58 }\end{array}$ & & & & & & & & \\
\hline Average & 7.9 & 6.7 & 4.5 & 8.0 & 7.6 & 8.1 & 6.8 & 4.5 \\
\hline Median & 8.6 & 7.6 & 4.6 & 7.8 & 7.8 & 8.3 & 7.6 & 4.9 \\
\hline $\begin{array}{l}\text { Nutridrik } \\
\text { n=54 }\end{array}$ & & & & & & & & \\
\hline Average & 7.4 & 4.7 & 3.7 & 7.5 & 6.6 & 7.7 & 7.6 & 4.9 \\
\hline Median & 7.9 & 4.8 & 3.7 & 7.9 & 6.5 & 8 & 8.2 & 4.9 \\
\hline RH n=52 & & & & & & & & \\
\hline Average & 7.1 & 6.6 & 4.6 & 7.4 & 7.3 & 7.4 & 6.1 & 4.6 \\
\hline Median & 7.6 & 7.1 & 4.8 & 7.5 & 8.1 & 7.7 & 5.4 & 5.0 \\
\hline
\end{tabular}

Without significant difference between the three products concerning the sensory variables sour and sweet (table 3 ). There was significant difference concerning the sensory variables of the three products (table 3).

Table 3: Result of Kruskal-Wallis test of the sensory variables for the three protein containing drinks in 41 patients with malignant haematological disease

\begin{tabular}{|l|l|l|l|l|l|l|l|l|}
\hline & Bitter & A glass & Sweet & Gritty & Metal & Salt & Sour & Thickness \\
\hline $\mathbf{C h i}^{\mathbf{2}}$ & 1.410 & 11.942 & 6.489 & 1.933 & 2.320 & 2.198 & 6.786 & 0.213 \\
\hline $\mathbf{D f}$ & 2 & 2 & 2 & 2 & 2 & 2 & 2 & 2 \\
\hline $\mathbf{P}$ & 0.494 & 0.003 & 0.039 & 0.381 & 0.314 & 0.333 & 0.0336 & 0.899 \\
\hline
\end{tabular}

The taste characteristics are shown in figure 1 . The differences in sweet, sour and sensory variables are illustrated. The VAS evaluation of the three products as a hole was not markedly different; their spider web had similar looks. We found no systematic relation between the VAS evaluations and the time passed from the preceding therapeutic session. 


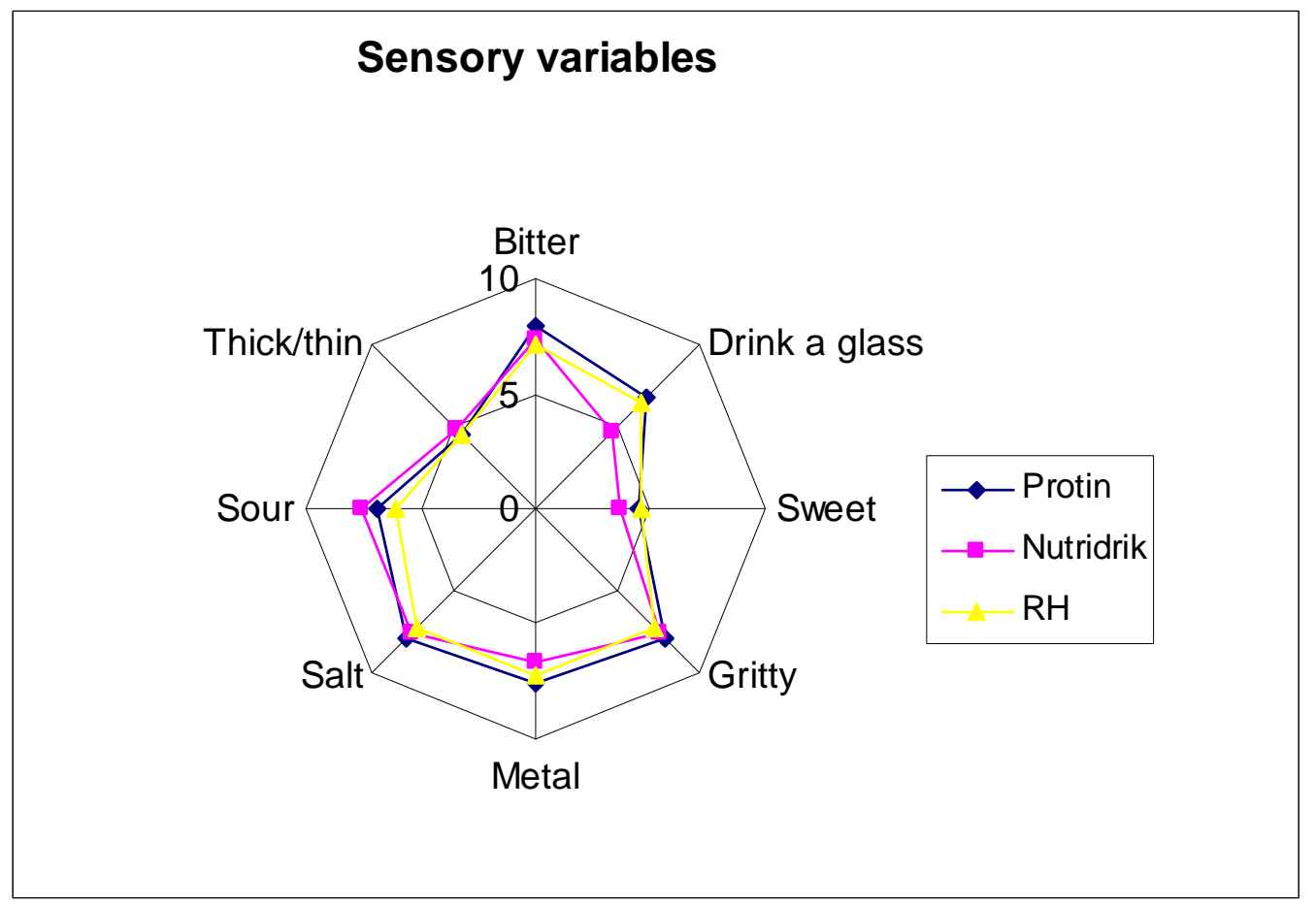

Figure 1: Nutritional supplements - Taste preferences divided in categories in patients with malignant haematological disease during active treatment with chemotherapy. Spider web of the sensory variables (Bitter, a glass, gritty, metal, salt, sour, sweet and thickness) for three products (Protin, Nutridrik and RH (= a fresh cold buttermilk based product produced in the hospital) in 41 patients with haematological malignant disease. Sensory parameters: 0 : Too much of the sensory variable. 10: Too little of the sensory variable. Acceptability - Drink a glass: 0: Not at all 10: No problem

The sensory differences of the three products

The results were detailed further (table 4). The patients judged that Nutridrik® had a significant sweeter taste than Protin $($ ) $(\mathrm{p}=0.041)$ and RH $(\mathrm{p}=0.021)$; the patients liked Protin $®(p=0.002)$ and $R H(p=0.005)$ significantly better than Nutridrik $\AA$. The patients judged that $\mathrm{RH}(\mathrm{p}=0.008)$ had a significantly more sour taste than Nutridrik ${ }^{\circledR}$. No significant differences were found between Protin $\AA$ and $\mathrm{RH}$ with regard to any of the sensory variables.

Table 4: Result of Mann-Whitney test for sour, sweet and the ability to ingest a glass of $150 \mathrm{ml}$ of the drink in 41 patients with haematological malignant disease.

\begin{tabular}{|l|l|l|l|l|l|l|}
\hline & \multicolumn{5}{|c|}{ Sensory variables } \\
\hline & A glass & & Sweet & & Sour & \\
\hline Protin vs. Nutridrik & $\mathrm{p}=0.002$ & & $\mathrm{p}=0.041$ & & $\mathrm{p}=0.192$ & \\
\hline Protin vs. RH & $\mathrm{p}=0.741$ & & $\mathrm{p}=0.598$ & & $\mathrm{p}=0.205$ & \\
\hline Nutridrik vs. RH & $\mathrm{p}=0.005$ & & $\mathrm{p}=0.021$ & & $\mathrm{p}=0.008$ & \\
\hline
\end{tabular}


Preferences (which drink do you prefer?)

The patients had a significantly higher preference for Protin $\AA$ compared to $\mathrm{RH}$ and especially to Nutridrik $($ : Protin $\AA$ vs. Nutridrik $\AA(p<0.001)$, Protin $\AA$ vs. RH $(p=0.049)$ and $\mathrm{RH}$ vs. Nutridrik $\AA$ $(\mathrm{p}=0.008)$.

Ability to drink $150 \mathrm{ml}$ (how difficult is it to drink one glass = $150 \mathrm{ml}$ ?)

Patients VAS-scored a significantly higher ability to drink $150 \mathrm{ml}$ of Protin $\AA$ and $\mathrm{RH}$ compared to Nutridrik® (table 4).

\section{Reproducibility}

Identical $(+/-10 \%$ in $\mathrm{cm})$ VAS-score was seen in 39 of the 41 patients (95\%), when blindly testing the same sample twice in random order mixed-in with the other samples.

\section{Viscosity}

The difference between the fresh milk products (Protin $\AA$ and $\mathrm{RH}$ ) and the commercial (Nutridrik®) was marked (Table 5 and fig 2).

Table 5: Viscosity measurements in milk-based oral, protein-enriched supplements. Nutridrik is a commercial drink with added minerals and vitamins, Protin is milk with added whey-protein and RH is buttermilk with eggs. The trendlines are shown in fig. 2. n and $\mathrm{m}$ are the indices of the powerlaw model with $\mathrm{m}$ as the general viscosity. $\mathrm{N}<1$ means that the liquid becomes more thick when stirred.

\begin{tabular}{|c|c|c|c|c|c|c|}
\hline & Trendline & $\mathbf{R}^{2}$ & $\mathbf{n}$ & SD & $\mathbf{m}$ & SD \\
\hline $\mathbf{R H}$ & $\mathrm{y}=0.43 \mathrm{x}+0.05$ & 0.995 & 0.400 & 0.020 & 1.205 & 0.090 \\
\hline Protin & $\mathrm{y}=0.52 \mathrm{x}-0.24$ & 0.996 & 0.516 & 0.005 & 0.655 & 0.113 \\
\hline Nutridrik & $\mathrm{y}=1.05 \mathrm{x}-1.58$ & 1 & 1.045 & 0,002 & 0.024 & 0.002 \\
\hline
\end{tabular}

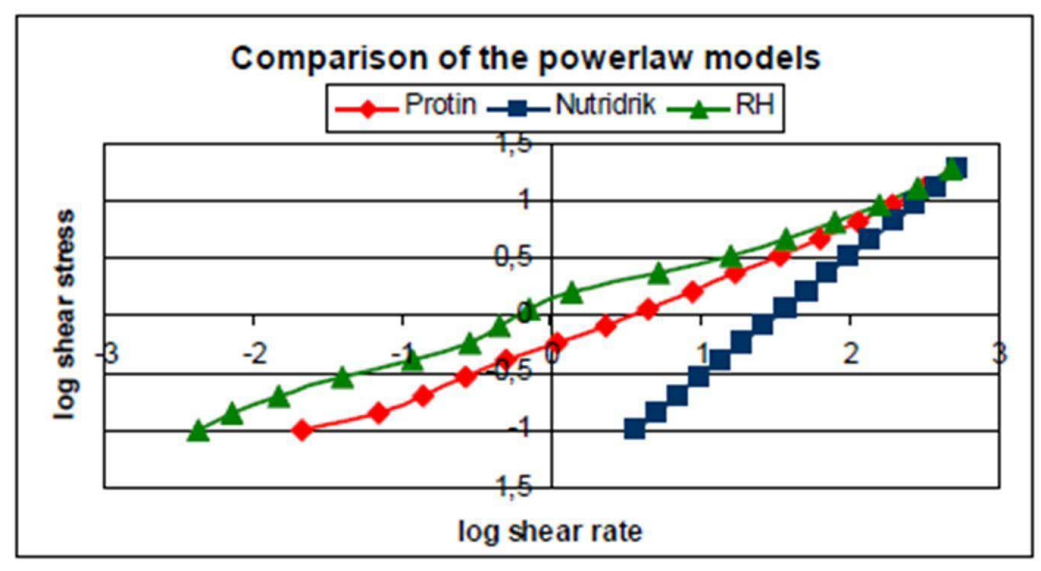

Figure 2: Nutritional supplements - Viscosity determinations. Shear stress (Pa) is the force that moves the liquid. Shear rate $(1 / \mathrm{s})$ is the velocity gradient. The difference in profile is marked between the commercial, milk-based Nutridrink and the fresh milk based drinks, Protin and RH.

\section{Statistics}

As results were distributed very skew, nonparametric methods were applied, Wilcoxon-, Mann-Whitney rank-sum tests, and Kruskal-Wallis test.

\section{Discussion}

Dysgeusia associated with weight loss due to lack of appetite and altered eating pattern influence the patient's Quality of life. Dysgeusia is caused by many factors, 
and simple studies of individual taste sensitivity using single taste stimuli (sweet, sour, salt, umami or bitter) are not considered predictive of dysgeusia nor of food aversions (Settle et al, 1978). The patients' preferences for fresh (no UHT) milk-based products (Protin and $\mathrm{RH}$ ) are similar to results found in other studies. Rahemtulla et al (2005) found no significant difference in preference for nutritional supplement due to disease or cytostatic treatment of 47 patients with gastrointestinal cancer and 47 healthy controls. Both groups had a preference for "Calshake", a fresh milk based product (No UHT) with strawberry flavour. Comparable results were reported by Darmon et al (2008) testing 109 malnourished inpatients, who preferred milk-based supplements to sweet and salty fruit-juice typed products. In a study of 60 patients with colorectal cancer using single tastestimuli, Kucz et al found a reduced sensitivity of taste compared to healthy controls (Kucz et al, 2008). This would indicate that cancer patients might prefer strongly flavoured foods. However, our results did not confirm such a hypothesis. Pelvic radiotherapy did not markedly affect supplement preference in a case-control study with healthy controls, but only $28 \%$ of the cancer patients received concomitant chemotherapy (McGough et al, 2006). In our setting, we found no systematic influence of the time-interval from the last chemotherapy or radiation therapy, but all the patients had mucositis. Even though individual differences in taste perception are many and complicated (Stevens, 1996), and despite the complex effects of disease, dissemination of disease, and treatment (Hutton et al, 2007), results seem to have some uniform directions. Fresh, milk based products seem to have a higher acceptability, but agreement is not complete. Several explanations might contribute. We know that hyperosmolarity is a problem for patients with mucositis, but all three drinks in our experiment were considerably hyperosmolar, making this factor an unlikely explanation. Texture was also markedly different (fig 2). Whether this is a determining factor or not cannot be answered with our present knowledge, but the enriched milk and the buttermilk- drink were very similar, and they were both evaluated as positive by the patients. Nutridrink showed different results, and was evaluated very negative. This may indicate that texture could be part of an explanation. We tried to interview the patients for details related to their own scoring, but gave it up, as most patients felt too tired after the testing sessions. Smell and viscosity as well as other textural variables could be factors involved.

The advantages of the commercial "fullnutritional" drinks are their content of micronutrients, their very long shelf-life, and the control procedures related to the manufacturing. The micronutrients might well be the reason for the reduced palatability, but future studies are needed to elucidate this.

All the published studies about taste disturbances in patients with malignant diseases are single meal tests. In the future, we would need long time studies using the results from the meal-studies to elucidate whether there are positive effects on nutritional status during the course of treatment, as compliance in the long run is determining the clinical value. Weight as well as body composition and quality of life should be used as outcome variables.

\section{Conclusion}

This study gives an indication of patients' preference with significant higher preference and palatability for fresh milk products than a commercial, milk based product. However, the basic sensory parameters studied with VAS gave no clear distinction between the three products, and the underlying basis for the preference is not obvious, and merits further investigations. The used test-method was well functioning with a very high reproducibility-rate.

\section{Acknowledgement}

We are grateful for the determinations of viscosity by Nancy Kjøbæk, Laboratory of Rheology and Texture, The Department of Food Technology, The Technical University 
of Denmark, Søltofts Plads, Building 227, 2800 Lyngby, Denmark.

\section{No conflicts of interest}

\section{Running head: taste preferences in cancer}

\section{References}

1. Darmon, P., Karsegard, V.L., Nardo, P., Dupertuis, Y.M. and Pichard, C. (2008) "Oral nutritional supplements and taste preferences: 545 days of clinical testing in malnourished in-patients." Clin Nutr27:660-665.

2. Epstein, J.B., Phillips, N., Parry, J., Epstein, M., Neville, T. and StevensonMoore, P. (2002) "Quality of life, taste, olfactory and oral function following highdose chemotherapy and allogeneic haematopoietic cell transplantation." Bone Marrow Transplant 30:785-792.

3. Hutton, J.L., Baracos, V.E. and Wismer, W.V. (2007) "Chemosensory dysfunction id a primary factor in the evolution of declining nutritional status and quality of life in patients with advanced cancer." J Pain Symptom Management 33:156-165.

4. Kucz, K., Maluck, S., Kohl, O., Wiese, M., Hanrider, D. and Weimann, A. (2008) „Taste perception and nutritional status of colorectal cancer patients under chemotherapy. Clin Nutr 3/suppl 1;100 (abstract).

5. McGough, C., Peacock, N., Hackett, C., Baldwin, C., Norman, A., Frost, G., Blake, P., Tait, D., Khoo, V., Harrington, K., Whelan, K., Jervoise, H. and Andreyev, N. (2006) "Taste preferences for

oral nutrition supplements in patients before and after pelvic radiotherapy: a double-blind controlled study." Clin Nutr 25:906-912.
6. Rahemtulla, Z., Baldwin, C., Spiro, A., McGough, C., Norman, A.R., Frost, G., Cunningham, D., Jervoise, $\mathrm{H}$ and Andreyev, N.(2005) "The palatability of milk-based and non-milk-based nutritional supplements in gastrointestinal cancer and the effect of chemotherapy." Clin Nutr 24:1029-1037.

7. Ravasco, P., Monteiro-Grillo, I., Vidal, P.M. and Camilo, M.E. (2003) "Nutritional deterioration in cancer: The role of disease and diet." Clin Oncol (R Coll Radiol) 15:443-450.

8. Ravasco, P. (2005) "Aspects of taste and compliance in patients with cancer." Eur J Oncol Nursing 9(suppl 2):S84-91.

9. Ravasco, P., Monteiro-Grillo, I., Vidal, P.M. and Camilo, M.E. (2005) "Dietary counselling improves patient outcomes: A prospective, randomized, controlled trial in colorectal cancer patients undergoing radiotherapy." J Clin Oncol 23:1431-1438.

10. Ravasco, P., Grillo, I.M. and Camillo, M. (2007) "Cancer wasting and quality of life react to early individualized nutritional counselling." Clin Nutr 26:7-15.

11. Rødbotten, M. (1997) "Kap.7: Metoder i sensorisk analyse" In "sensorisk analyse - Bedømmelse af næringsmidler" Sensorisk studiegruppe. 2. ed., Universitetsforlaget Oslo, Norway

12. Settle, R.G., Quinn, M.R. and Kare, M.R. (1978) "Evaluation of Cancer Patients, including Interim Report 1 on Task 1 and 2 and analysis from Task 4. Contract no. NOlCP-6579l". Report of the August 4, 1978, Meeting of Gustatory, Philadelphia: Monell chemical Senses Centre, University of Pennsylvania.

13. Stevens, D.A. (1996) "Individual differences in taste perception." Food Chemistry 56:303-311. 